\title{
A EDUCAÇÃO QUE LEVA AO TRABALHO - O TRABALHO QUE LEVA À ESCOLA: SUPERANDO A DICOTOMIA ENTRE EDUCAÇÃO E TRABALHO
}

Odair França de Carvalho ${ }^{1}$

\begin{abstract}
RESUMO: A educação nas prisões foi objeto de discussôes no Ministério da Educação nos anos 2000, no contexto do movimento de debate educacional que incorporou grupos, movimentos sociais e representantes de segmentos historicamente excluídos das políticas públicas do Estado brasileiro. Este artigo apresenta reflexóes desenvolvidas em pesquisa de doutorado cujo objetivo foi analisar experiências educativas, desenvolvidas por educadores no interior de escolas do sistema prisional de Sáo Paulo, tendo como cerne a experiência desenvolvida pela Fundação Estadual de Amparo ao Trabalhador Preso (FUNAP). Os resultados apresentam pontos positivos no que tange a oportunizar ao homem preso a vivência e a possibilidade da construçáo de uma nova identidade - a de educador - e a luta pela preservação de um espaço que busca resistir à cultura prisional - a escola. As análises indicam precariedade na formação dos educadores, revelando uma política pública educacional e laboral alicerçada a partir da exploração da mão de obra carcerária.
\end{abstract}

Palavras-chave: Educação. Monitores educadores. Trabalho.

${ }^{1}$ Universidade Federal de Ouro Preto (UFOP) - Ouro Preto (MG), Brasil.

E-mail: carvalhouab@gmail.com

DOI: 10.1590/CC0101-32622016162655 


\title{
Education that leads to work - work that leads to school: overcoming the dichotomy between education and work
}

\begin{abstract}
Education in prisons was the subject of discussions in the Ministry of Education in 2000, in the context of the educational debate that incorporated groups and social movements, representatives of historically excluded segments of the public policies of the State. This paper presents reflections developed in a doctoral research whose goal was analyze educational experiences, developed by educators within the prison system schools of São Paulo, with the core experience developed by FUNAP. The results present positive points with regard to encouraging man arrested the experience and the possibility of building a new identity of-educatorand the struggle for the preservation of an area that seeks to resist the prison culture-school. The analysis indicates insecurity in training of educators revealing a public education and employment based from the exploitation of prison labor.
\end{abstract}

Keywords: Education. Monitors Educators. Job.

\section{INTRODUÇÃO}

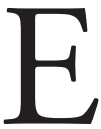

ste artigo apresenta parte dos resultados da tese de doutoramento "Entre a cela e a sala de aula: um estudo sobre experiências educacionais de educadores presos no sistema prisional paulista”, defendida em 2014 no Programa de Pós-Graduação em Educação da Universidade Federal de Uberlândia (UFU), cujo objetivo foi analisar experiências educativas desenvolvidas por monitores educadores no interior de escolas do sistema prisional de São Paulo.

Inspirados na história oral temática (MEIHY, 2002), registramos, por meio de entrevistas orais que foram gravadas, as vozes dos sujeitos idealizadores e educadores presos envolvidos nas experiências educativas.

Fizeram parte do universo pesquisado 30 sujeitos, sendo 28 homens e 2 mulheres, de 5 penitenciárias masculinas e 1 feminina 
do Sistema Penitenciário Paulista, e 3 funcionários (gestor, assessor e ex-dirigente de regionais) da Fundação Estadual de Amparo ao Trabalhador Preso (FUNAP). Elegemos como lócus de pesquisa seis unidades prisionais do Estado de São Paulo, sendo cinco masculinas e uma feminina. A escolha do Estado de São Paulo justifica-se porque possui a maior população carcerária do país (209.053 presos, INFOPEN, 2014) e desenvolve experiências com o trabalho educacional e laboral com presos desde a década de 1970, por meio da FUNAP, responsável por essas atividades. Essas unidades também foram escolhidas por desempenharem atividades educacionais consideradas exitosas, por meio de (monitores) presos educadores, no desempenho de suas atividades ou em seu interior.

A pesquisa ancorou-se na abordagem da pesquisa qualitativa, pautada nos procedimentos da história oral temática (MEIHY, 2002) em uma visão interdisciplinar. Para atingir os objetivos propostos foram escolhidos os seguintes procedimentos metodológicos: pesquisa bibliográfica, análise de documentos escritos, tais como leis, diretrizes e material didático, e realização de entrevistas orais com os presos educadores e gestores. Recorremos aos aportes teóricos dos estudos culturais, da pesquisa narrativa, da formação de professores, dos saberes docentes e da Educação de Jovens e Adultos (EJA).

$\mathrm{O}$ artigo está organizado em três partes. Na primeira, apresentamos um breve histórico da instituição responsável pela educação e o trabalho no interior das unidades prisionais do Estado de São Paulo, para compreendermos os jogos de forças na dinâmica interna do sistema. $\mathrm{Na}$ segunda parte, com o intuito de refletir os achados da pesquisa, são apresentadas as narrativas dos monitores educadores acerca da educação e do trabalho. Por fim, tecemos algumas consideraçóes.

\section{A FUNDAÇÃO ESTADUAL DE AMPARO AO TRABALHADOR PRESO E A CONSTITUIÇÃO DA EDUCAÇÃO E DO TRABALHO NO SISTEMA PRISIONAL PAULISTA}

Missão: contribuir para a inclusão social de presos e egressos, desenvolvendo seus potenciais como indivíduos, cidadáos e profissionais. (FUNAP, 1994) 
No ano de 1976, o Governo do Estado de São Paulo instituiu, pela Lei $\mathrm{n}^{\circ} 1.238$, de 22 de dezembro de 1976, a FUNAP, entidade que ficaria responsável pela educação e pelo trabalho no sistema prisional paulista, retirando a responsabilidade da Secretaria de Educação do Estado. Assim, criou-se a FUNAP.

A FUNAP é um órgão que completa a Administração Penitenciária no Estado de São Paulo. No âmbito executivo de sua composição, é gerida por um conselho curador, órgão de deliberação, e uma presidência, que é o órgão executivo composto por 19 membros, com mandato de 4 anos, podendo ser renovado por mais 1 . Sua presidência é ocupada por um membro designado pelo governador do Estado.

A educação nas prisóes no Estado de São Paulo, de 1970 a 1979, esteve vinculada às normatizaçóes da rede regular de ensino a cargo da Secretaria de Educação do Estado. Assim, os presídios que ofertavam educação estavam ligados a uma escola pública estadual e às suas normas de funcionamento. A educação ofertada às crianças e aos jovens era a mesma dos presídios, tanto em aspectos curriculares e metodológicos como da gestão escolar. Português (2001) esclarece que esse modelo não atendia às necessidades dos sujeitos presos e que ignorava as contribuiçôes da produção acadêmica sobre a Educação de Jovens Adultos e as novas metodologias sobre o alfabetizar, além de não respeitar as peculiaridades desse público, notadamente, a permanência e a rotatividade dos presos.

Criada em 1976, só no ano de 1979 a FUNAP assumiu as atividades educacionais e laborais nos presídios. Essa mudança provocou uma desarticulação das atividades educativas dentro do sistema. A Secretaria de Educação estava organizada e presente em todas as regióes do Estado. Por outro lado, possibilitou à FUNAP a busca de parcerias com outras instituiçóes, sendo as primeiras feitas com o Programa Mobral, a Fundação Educar e a Fundação Roberto Marinho.

Segundo Português (2001, p. 106),

O motivo pelo qual a Secretaria de Educaçáo ausentou-se da educação de adultos presos não foi, contudo, pedagógico ou especificamente metodológico. Em 1979, o governador de Estado de São Paulo, Paulo Egídio Martins 
(1979-1982), interrompeu todos os comissionamentos dos servidores incluindo, portanto, os professores lotados nos estabelecimentos penitenciários [...]

Até o final de 1979, a educação básica ofertada no interior dos presídios

era executada por professores comissionados da Secretaria da Educação e obedecia ao calendário escolar das escolas oficiais, com seriação anual e com o mesmo material didático aplicado às crianças (RUSCHE, 1995, p. 10).

Não respeitava, assim, os aspectos culturais, sociais e políticos que compunham esse complexo sistema.

Português (2001, p. 106) afirma ainda que:

O exercício da docência naquelas condiçóes implicava em gratificação salarial, a título de periculosidade e insalubridade, que girava em torno de $30 \%$ dos vencimentos. Exercidos cinco anos na função, esse percentual era incorporado ao salário, não mais podendo ser dele extraído. Assim, os professores que estavam próximos de se aposentarem, eram privilegiados nos comissionamentos, de forma a poder incorporar este adicional aos seus provimentos indefinidamente.

Nesse ano, foram cessados todos os cargos comissionados no governo de Paulo Egídio Martins (1979-1982), atingindo os professores que trabalhavam nesses estabelecimentos. Esse fato concorreu para que ocorresse, de forma experimental, a docência desempenhada pelos agentes penitenciários. Essa ação provocou um mal-estar no interior das unidades prisionais. Como desenvolver a "ação disciplinadora" de agente em um período e a "ação libertadora" como educador? Ademais, ocorreram problemas de caráter legal com a própria Secretaria de Administração Penitenciária devido ao acúmulo de funçôes.

$\mathrm{Na}$ tentativa de solucionar a situação, foi gestada a "figura do educador”, que seria responsável por dar continuidade às açóes educacionais dentro das prisóes. Esses sujeitos eram selecionados entre a massa 
carcerária: deviam possuir o ensino fundamental incompleto ou o ensino médio. Essa experiência nasceu no seio do Regime Militar, quando ocorreu a prisão de intelectuais, políticos e estudantes universitários, condenados à pena de reclusão por crimes políticos. Iniciava-se, assim, o desenvolvimento de práticas educativas e culturais com a "massa carcerária" nesse momento, majoritariamente composta por analfabetos e semianalfabetos (SILVA; GÓES; ROCHA, 2007).

Nos anos 1980, a função de contratar educadores e ofertar a educação para os detentos passou a ser responsabilidade da FUNAP. Nesse percurso, evidenciou-se um período de desarticulação da oferta de educaçáo no sistema. Fato esse complexificado pela aprovação da Lei no 7.210, de 11 de julho de 1984, que instituiu a Lei de Execução Penal, que garantiu a assistência educacional ao preso.

A FUNAP passou a ter a responsabilidade de planejar, desenvolver e avaliar atividades pautadas em programas e projetos em quatro áreas: Assistência Jurídica, Educação, Cultura e Profissionalização e Trabalho.

A oferta de cursos profissionalizantes, segundo dados oficiais, centrava

[...] esforços na realização de cursos profissionalizantes com certificação que invistam na perspectiva de formação integral (gestáo, cidadania, mercado, empreendedorismo, cooperativismo, etc.), buscando sempre a especialização de forma a criar real possibilidade de ingresso no mercado formal de trabalho. (FUNAP, 2010)

As atividades laborais estão alicerçadas em um "programa de alocação de mão de obra” que propicia geração de renda e experiência profissional, abrindo postos de trabalho para os presos e egressos tanto em órgáos públicos, empresas privadas e terceiro setor como nas oficinas de produção próprias: confecçáo de uniformes, com central de corte de tecido industrial; tapeçaria de cadeiras fixas e giratórias; fabricação de móveis escolares e cadeiras universitárias; marcenaria para fabricação de kits para reforma de móveis escolares; metalurgia para fabricação de móveis de escritório; montagem de móveis de escritório; fabricação de papel artesanal; e, por fim, reciclagem 
de lixo sólido. Destacamos que essas atividades iniciaram-se com os trabalhos manuais (artesanato) das prisioneiras do presídio feminino da capital.

De acordo com a FUNAP, as ações laborais possuíam duas vertentes:

1a) Postos de trabalho para os presos, em empresas públicas e privadas, prestando ao contratante orientação técnica por ocasião da elaboração do contrato, na seleção e no acompanhamento dos presos trabalhadores e supervisionando a utilização dos equipamentos de segurança;

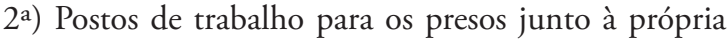
Fundação, com remuneração mínima no valor de $\mathrm{R} \$ 395,25$ (trezentos e noventa e cinco reais e vinte e cinco centavos), para jornada de 8 (oito) horas, sendo locados nas áreas de educação e cultura, como monitores de educação, sala de leitura e projetos; ou nas Unidades de Produção e Qualificação Profissional, instaladas no interior das unidades penais. (FUNAP, 2010)

Devido à baixa remuneração e à ausência das contribuiçóes trabalhistas e impostos, observa-se uma crescente ampliação na alocação da mão de obra de presos no mercado. Isso se verifica nos dados oferecidos pela própria fundação nos anos descritos no Programa de Alocação de Mão de Obra, conforme demonstra o Quadro 1.

\section{Quadro 1}

Prisioneiros em atividades laborais

\begin{tabular}{|c|c|}
\hline Ano & Postos de trabalho \\
\hline 2006 & 33.918 \\
\hline 2007 & 41.520 \\
\hline 2008 & 39.369 \\
\hline 2009 & 39.904 \\
\hline 2010 & 45.000 \\
\hline 2011 & 45.000 \\
\hline 2012 & 46.000 \\
\hline 2013 & 48.028 \\
\hline
\end{tabular}

Fonte: Fundação Estadual de Amparo ao Trabalhador Preso - FUNAP, 2014. 
Ao relacionar o número de presos que trabalham e estudam com a população carcerária do Estado, obtemos a seguinte proporção: 26,5\% de presos em atividade laboral e apenas 9,24\% dedicando-se ao estudo. De acordo com os dados socializados pelo Infopen (junho, 2014), apenas $16 \%$ da população prisional do país trabalha. Entre estudar e trabalhar, até o ano de 2014, os presos, na maioria das vezes, optavam por trabalhar. Para Penna (2003, p. 116),

[...] o trabalho oferece a possibilidade salário e remição, ou seja, atrativos mais concretos para os detentos, que, se tiverem que optar entre estudar e trabalhar, escolhem a segunda alternativa. Os ganhos com a escola se configuram a longo prazo.

A remição da pena pelo estudo, no Brasil, foi implantada somente em 2011, com ressalva ao Estado do Rio de Janeiro. Julião (2009), em sua tese de doutorado, demonstrou que, nesse Estado, os detentos preferiam estudar, fato constatado desde o ano 2000, quando a Justiça do Rio de Janeiro passou a conceder o benefício de remição. Essa forma garante aos presos o direito de acumular os dois benefícios, o que deve se ampliar em âmbito nacional.

Em uma trajetória de avanços e retrocessos, evidenciamos que, no início, a fundação ancorou suas açóes no aspecto laboral, que tinha como função principal contribuir para a preservação e a manutenção da disciplina dentro das unidades. $\mathrm{O}$ trabalho era usado como estratégia para o controle penitenciário. Também constatamos que a vinculação externa da fundação com outras instituiçóes e açôes, como a participação em exames públicos de certificação (ENCCEJA e ENEM) e a parceria com as ONGs, a Fundação Roberto Marinho, o SENAI e as prefeituras, evidenciou a busca de alternativas para a implantaçáo de um programa educativo que contribuísse para a melhoria da condição em que se encontra o cidadão preso, sendo que procura romper com a impermeabilidade que as instituiçóes totais impóem aos estranhos (GOFFMAN, 1987). Assim, a fundação, para adentrar a esse complexo sistema, foi assumindo responsabilidades, como aquelas citadas (assistência jurídica, atividades culturais, esportivas, entre outras), como "moeda de troca", no intuito de obter colaboração dos dirigentes das unidades prisionais, dos diretores e, principalmente, da própria Secretaria de Segurança Pública para desempenhar as atividades educativas. 
A aprovação das "Diretrizes Nacionais para a oferta de educação para jovens e adultos em situação de privação de liberdade nos estabelecimentos penais" (2010), a alteração na Lei de Execuçóes Penais (LEP) ${ }^{1}$, que instituiu a diminuição da pena para o preso que estudar em atividades dos ensinos fundamental, médio, profissionalizante, superior, de modo presencial e a distância, e a transferência da responsabilidade (2013) pela oferta de educação nos estabelecimentos penais pela Secretaria de Educação do Estado de São Paulo (SEE/ SP) produziram impactos nas atividades da FUNAP. Em 2012, a Secretaria de Educação assumiu a responsabilidade pela educação no sistema prisional paulista. A FUNAP voltou seus trabalhos às atividades laborais/educacionais, lançando, em junho de 2013, uma nova política pública de atendimento aos encarcerados, o Programa de Educação para Trabalho (PET).

No final de 2013, o PET apresentava o seguinte cenário: 7.800 inscritos, 204 salas de aula e 374 turmas. Destacamos que a instituição aproveitou os presos monitores/educadores para desenvolver as atividades de formação.

Essa breve contextualização da história da FUNAP nos expóe a tentativa de edificação de uma política de implementação de um programa de educaçáo em espaços prisionais, conjuntamente com outras instituiçóes do próprio Estado de São Paulo, constituindo, assim, um repertório de experiência e saberes sobre a EJA, dentro do sistema prisional paulista, nos últimos 30 anos.

\section{ANÁLISE E RESULTADOS}

Destacamos que os monitores investigados, em relação à grande massa carcerária, apresentam um índice de escolaridade alto, pois $85 \%$ possuem o ensino médio, e $15 \%$, o ensino superior. Seis dos participantes da pesquisa concluíram seus estudos no sistema prisional: um concluiu os ensinos fundamental e médio, quatro concluíram o ensino médio, e um deles concluiu o ensino superior, pois cursou Pedagogia por educação a distância (EaD), na Penitenciária de Araraquara. Todos motivados, inclusive, pela possibilidade de ser monitor preso.

Se fizermos uma comparação do nível de escolaridade ${ }^{2}$ dos monitores com a massa carcerária do Estado de São Paulo — que era de 170.916 
presos (naquele momento, representava 34\% do total nacional), de acordo com dados do Ministério da Justiça/Infopen (Censo, 2010) —, notaremos que, em relaçáo aos demais presos, temos um panorama positivo.

Quanto ao trabalho que exerciam fora das prisóes, entendido aqui como exercício de uma atividade laboral remunerada, $100 \%$ dos entrevistados afirmaram que estavam trabalhando quando foram presos, sendo $80 \%$ no mercado formal e $20 \%$ na informalidade. Dentre as atividades, apareceram as de: músico (1), caminhoneiro (2), office-boy (3), microempresário (2), vendedor e comprador de carro (1), professor $(3)^{3}$, eletricitário (1), piloto de aviáo (1), despachante (1), técnico em informática (1), avaliador de joia (1), autônomo (3), pintor (1), marceneiro (1), técnico de TV a Cabo (1), porteiro (1), analista de informática (1), policial (1) e divulgador externo (1).

Assim, evidenciamos que os monitores exibem um perfil diferenciado do restante dos presos, não só pelos dados apresentados, mas também na maneira de falar, sem vícios de linguagem, na sua conduta com os iguais e com os funcionários e, principalmente, no comprometimento desses homens e mulheres com o exercício das atividades educacionais.

Os colaboradores expressam sentimentos de respeito e carinho pelos professores. Memórias que fazem parte da constituição de sua identidade de homem, preso, pai, filho, aluno e educador. Como afirma Bosi, "pois o que se lembra são momentos vividos, respostas pessoais, em suma, a melodia do passado interpretada pelo presente" (BOSI, 2009, p. 48).

É importante relatar, ainda, que eles descreveram o ambiente escolar como um local social de encontros de amizades, de sonhos e de desafios.

Quando falam sobre a escola, percebemos as marcas que essa instituição deixa na vida dos sujeitos que por ela passam. Contudo, é visível que a escola falhou, uma vez que a maioria dos investigados, de algum modo, a abandonou, pois, de uma maneira mais ampla, a instituição não contemplava a vida. E, desse modo, a escola acabou contribuindo para o crescimento das estatísticas prisionais, por excluir esses sujeitos que, em algum momento, deixaram de estudar por não fazer diferença em suas vidas. 
Ao serem perguntados sobre o que leva um preso a estudar ou voltar a estudar, os colaboradores apresentaram as seguintes justificativas:

Acredito que a minoria volta por acreditar na educação e por querer mudanças. A maioria quer a remição. (Educador 11)

Existe um que estuda porque ele não quer ficar no pavilhão, já existe outro que estuda, porque existe a necessidade dele terminar o estudo dele. Existe outro que estuda porque quer adquirir o conhecimento. (Educador 5)

Segundo os monitores, são diversos os motivos que levam um preso a voltar a estudar. Primeiro, nas concepçóes deles, é o interesse pela remição de pena ${ }^{4}$, por ser o espaço da escola um ambiente diferenciado; para adquirir conhecimento e também para quando sair da cadeia ter uma oportunidade no mercado de trabalho; por ser uma oportunidade de reflexáo; pela capacidade de mudança que a escola pode promover na vida de uma pessoa, tanto no campo pessoal como profissional; e pela própria falta de oportunidades que o sistema prisional oferece ao detento, no campo da ocupação — ou trabalha ou estuda — ou, ainda, por não ter nada o que fazer, nada no raio/pavilhão.

Eu queria conhecer mais. Não na parte do estudo, mas na parte do conhecer tipo, pessoas, outras pessoas, principalmente de fora também, queria sair um pouco desse mundo. (Educador 4)

Busco uma mudança, a mudança na vida, pois quando eu era jovem, eu não tive escolhas, [...] fui procurar algo lá fora que não seja a esquina, a viela, o revólver, a droga. [...]. (Educador 8)

Precisa da escolaridade; para ele mudar a história dele, ele precisa da educaçáo, tendo um conhecimento melhor. (Educador 10)

Outros disseram que voltam para a escola pela oportunidade que não tiveram quando jovens, seja por questóes sociais ou financeiras. Essa afirmação representa o que a maioria pensa: "Para mudar a história dele, ele 
precisa da educação!” (Educador 10). Apareceu também a velha dicotomia entre o trabalhar e o estudar, não mais pela remição, mas sim pela sobrevivência dentro da cadeia, porque "apenas café, almoço e jantar é pouco", precisamos de "material de limpeza e outras coisas". Assim, uns acabam optando por trabalhar, mas pareceu-nos que, para aqueles que querem deixar o mundo do crime, essa situaçáo não lhes impede de estudar. O relato a seguir demonstra a contradição: "Por isso não estudam aqui dentro, priorizando o trabalho também, porém não é uma justificativa palpável, porque aqui tem quem trabalha e estuda também" (Educador 3). Os presos desenvolvem atividades laborais diversas, como: costura de bola, trabalhos na própria prisão (cozinha, faxina, serviços de jardinagem, pintura), produção de roupas, sacolas ecológicas, prendedores de roupa, móveis escolares. A Lei de Execução Penal no 7.210, de 11 de julho de 1984, em seu Art. 29 diz: "O trabalho do preso será remunerado, mediante prévia tabela, não podendo ser inferior a 3/4 do salário mínimo" (BRASIL, 1984). A maior parte da oferta de trabalho advém de microempresas, cujo interesse se deve pelos não pagamentos dos direitos trabalhistas ${ }^{5}$, dados esses que vem ao encontro dos resultados da pesquisa de Mello (2010) no sistema prisional paraibano, ao destacar que as principais atividades no interior da prisão são costura de bola, cozinha, limpeza, manutenção e artesanato, oportunidades essas com poucas vagas disponibilizadas para trabalhar e a salários irrisórios. Nesse aspecto, Hassen (1999, p. 185) afirma que "[...] o trabalho que acontece na prisão é remunerado de maneira táo insignificante que se assemelha ao trabalho escravo". Para o autor, o trabalho na prisão se contrapóe ao ócio, levando à ocupação do tempo e da mente, e possibilita melhorias na condição de permanência na instituiçáo prisional ao gerar um salário e a remição.

A motivação para os estudos vem dos mais diversos estímulos e necessidades. Chamou-nos a atençáo a objetividade do Educador 1, que caracterizou o panorama observado na maioria das unidades pesquisadas, em relação ao preenchimento de vagas e oferta:

Na minha visão, se você pegar, dentro do raio, a porcentagem é bem baixa, só $10 \%$ estudam. A população carcerária, dentro do raio, não preenche todas as vagas para estudar, nem todo mundo quer estudar, a motivação vem de dentro de cada um, é particular. (Educador 1) 
Deixou claro que, para uma grande porcentagem dos detentos, o estudo não é atrativo por vários fatores.

Também queríamos saber o porquê de estudar, aprender dentro do presídio.

Primeiro porque aqui você tem tempo, eu creio que está mais fácil estudar aqui dentro da prisão do que lá fora, aqui sobra tempo para ler, estudar, e também com o conhecimento a gente pode ajudar os que têm mais dificuldades. (Educador 3)

Nós, hoje, temos um tempo de reflexáo que a cadeia nos dá esse tempo de reflexão, nós temos, e a escola é um caminho de mudar a vida. (Educador 10)

Os entrevistados ainda afirmaram que por terem mais tempo, e para transformá-lo em algo útil, vão à "escola". Por estarem em proximidade com a escola, estudar na prisão se torna mais fácil. "Alguns vêm para buscar caderno, caneta, vêm para passear um pouco, para sair daquela rotina, mas tem aqueles que vêm com o objetivo de aprender e de ser alguém, eles têm essa esperança”" (Educador 7).

Outros informaram que alguns de seus alunos, que não recebem visitas ou não trabalham, acabam indo uma semana e, depois que conseguem o material, não voltam mais. Segundo eles, a cadeia, para aqueles presos que não têm trabalho ou apoio da família, é muito dura. E por que estudar na prisão?

Porque sem estudo, sem conhecimento, a gente não é nada, mas alguns só querem a remição. (Educador 8)

É a única forma de crescer, de ser livre, esta é a realidade, de ser feliz, também nesse lugar triste, negativo, esta é a realidade, é uma felicidade para mim, compartilhar, explicar com as pessoas não são alunos são pessoas. (Educador 9)

Outros veem a escola como forma de crescimento, uma oportunidade de mostrar que querem mudar, pois isso será um meio de buscar um trabalho melhor quando saírem da prisão. Eles reconhecem a 
educação como uma possibilidade de conquistar um lugar melhor na sociedade. Consideram, ainda, que um dos caminhos para a reabilitação é o investir na educação.

As narrativas nos contam que os monitores não separam o que leva um preso a voltar estudar na prisão do "para que estudar?". Elencaram os mais variados motivos para um detento voltar a estudar, desde adquirir independência perante os outros, nas situaçóes mais corriqueiras da prisão como ler, escrever bilhetes, cartas, solicitar atendimento, até mesmo por falta de outras atividades. Essas foram encontradas por Leite (1997), como ele assim descreve:

[...] principalmente aqueles que cursavam o PEB I e II ( $1^{\text {a }}$ e $2^{\text {a }}$ séries), o que estava por trás do seu interesse pelo estudo era o desejo e a necessidade de se comunicar com os amigos e familiares através de cartas, sem ter que depender de outros presos. Na prisáo, ler e escrever significa mais liberdade e privacidade. Quem não sabe pede, e quem pede, deve. Na prisão até favor é dívida. E dívida é risco de vida. (p. 77)

Razóes essas que levam a um caminho de autonomia e solidariedade, pois também buscam ajudar o próximo, e por ser um espaço que proporciona o contato com o mundo exterior (professores da rua). Concordamos com Onofre (2008, p. 13), ao afirmar que:

É preciso afastar-se, no entanto, de qualquer postura ingênua em relaçáo ao papel da escola dentro do sistema prisional, mas não há como negar que, nesse espaço, o homem aprisionado, muitas vezes, busca sua identidade e o diálogo, reconstrói a sua história e valoriza os momentos de aprendizagem, tendo, portanto, o direito a uma escola competente, solidária, produtiva e libertadora.

Silva (2000, p. 36) afirma que a escola é um espaço de possibilidades no interior do presídio:

A escola dentro do sistema penitenciário possibilita uma forma diferente de trabalhar com o detento, esse setor pode ser uma alternativa para o aluno que procura deixar ou evi- 
tar ser inserido no que podemos chamar de "criminalidade". Uma educação eficiente pode possibilitar ao aluno um espaço de reflexão e de esperança nos objetivos almejados. Pode não ser algo definitivo, mas é um passo à frente em um caminho que terá para esse um novo começo.

Indagamos sobre a vida escolar dentro do presídio e obtivemos respostas que demonstram trajetórias de pessoas comuns, que passaram pela escola e tiveram seus percalços como a maioria dos jovens e adultos deste país, que ora se dedicam à escola, ora se dedicam ao trabalho.

Por outro lado, ao falarem sobre os prisioneiros e a prisão, o panorama é outro. Demonstram ser pessoas cheias de mágoas, de descrédito e de sentimento de revolta, não por estarem presos, mas pela condição em que vivem. Mostraram que a instituição poderia ser bem melhor, se não houvesse o preconceito, os pós-julgamentos e, principalmente, se a justiça fosse mais rápida e se não houvesse o problema da superlotação ${ }^{6}$, como já citamos, com números. Asseguraram ainda que é uma condição estar, e não uma determinação estar preso.

\section{CONSIDERAÇÕES FINAIS}

As reflexóes aqui expostas, para além de uma ode à proposta desenvolvida pela FUNAP ao implantar um projeto que teve monitores presos no papel de educadores, nos leva a reconhecer e valorizar essa experiência como algo que transformou esses homens e mulheres em "sujeitos da experiência" (LARROSA, 2002), na busca de um "ser mais" em um constante processo de humanização (FREIRE, 1996). Deixando marcas e vestígios que nos revelam a vocaçáo do homem de ser mais e expóem a sua condição de inacabado e inconcluso (FREIRE, 1979).

Os dados revelam congruências que dialogam com outros estudos (MENOTTI, 2013; JESUS, 2010; PENNA, 2003) que destacam o papel dos monitores à frente do exercício da docência, mas também enumeram as dificuldades e limitaçóes enfrentadas por esses atores dentro do sistema prisional. Evidenciamos alguns pontos: o reconhecimento do espaço escolar como local diferenciado dentro da prisão, como espaço de resistência no ambiente prisional, e o exercício da docência como es- 
tratégia de sobrevivência, além do prestígio e da distinção que a figura de educador os proporciona, a busca pela remição de pena, ter uma ocupação, e a edificação de saberes no decorrer da sua atuação, fatores esses que não escondem as dificuldades que o Estado e a FUNAP vêm enfrentando para a implantação e consolidação de uma política pública de jovens e adultos em regime privação de liberdade no Estado de São Paulo que leve o homem preso à emancipação.

Desde 2013, dois anos após a aprovação das diretrizes, o Estado assumiu a responsabilidade pela oferta de educação no interior dos presídios $^{7}$, pois, em vez de monitores presos, criaram-se as escolas vinculadoras, com professores da rede estadual. Podemos afirmar, ao reconhecer a Educação em Prisóes como uma ramificação da EJA, que ela apresenta as mazelas na sua constituição como direito do cidadão preso, ambas lutam para estabelecer a edificação de um diálogo entre as esferas federal e estadual, fato que pode ser observado no processo de elaboração dos Planos Estaduais de Educação em Prisóes. No caso de Sáo Paulo, tais planos travaram perante as dificuldades no diálogo entre a Secretaria de Educação e a Secretaria de Administração Penitenciária.

Portanto, o espaço escolar e a docência para além de uma atividade laboral se revelam como um ato de resistência da mulher e do homem preso, como destaca Rocha: "As pessoas presas conseguem manter a identidade, os valores de origem e grupais, a perspectiva de vida e de liberdade, a despeito das longas condenaçóes e de todos os fortes e rigorosos meios de controle e sujeição utilizados pela instituiçâo penitenciária" (1994, p. 3), tornando-se, para alguns, locais de empoderamento diante do controle, da dominaçáo e da anulaçáo do sujeito.

No transitar pelas memórias e experiências desses educadores, concluímos que o tornar-se educador é um processo longo que requer ousadia, dedicação, encantamento, disciplina, amor pelo que faz, características essas manifestadas nas vozes dos monitores. Assim, acreditamos que a singularidade e o sucesso dessa experiência se devam principalmente ao engajamento desses homens e mulheres educadores. Como nos ensinou Freire, "[...] se a educação não pode tudo, alguma coisa fundamental a educação pode. Se a educação não é a chave das transformações sociais, não é também simplesmente reprodutora da ideologia dominante" (1996, p. 112). 


\section{REFERÊNCIAS}

BODGAN, R.; BIKLEN, S. Investigação qualitativa em educação. Porto: Porto Editora, 1994.

BOSI, E. Memória e sociedade: lembranças de velhos. $3^{\text {a }}$ ed. Sáo Paulo: Companhia das Letras, 1994.

. O tempo vivo da memória: ensaios de psicologia social. São Paulo: Ateliê Editorial, 2009.

BRASIL. Resolução n. 2, de 19 de maio de 2010. Diretrizes Nacionais para a oferta de educação para jovens e adultos em situação de privação de liberdade nos estabelecimentos penais. Brasília, 2010.

. Lei n. 7.210, de 11 de julho de 1984. Lei de Execuçáo Penal.

- Parecer das Diretrizes Nacionais para a oferta de educação para jovens e adultos em situação de privação de liberdade nos estabelecimentos penais. Relator: Adeum Hilário Sauer. Brasília, 2010.

FREIRE, P. Educação e Mudança. Rio de Janeiro: Paz e Terra, 1979.

. Pedagogia da Autonomia. 29a ed. Rio de Janeiro: Paz e Terra, 1996.

GOFFMAN, E. Manicômios, Prisóes e Conventos. $7^{\text {a }}$ ed. São Paulo: Editora Perspectiva, 1987.

HASSEN, M.N.A. O Trabalho e os dias: ensaio antropológico sobre trabalho, crime e prisão. Porto Alegre: Tomo Editorial, 1999.

JULIÃO, E.F.A ressocialização através do estudo e do trabalho no sistema penitenciário brasileiro. Tese (Doutorado em Ciências Sociais) - Universidade do Estado do Rio de Janeiro, Rio de Janeiro, 2009.

LARROSA, J. Notas sobre a experiência e o saber da experiência. Revista Brasileira de Educação, Campinas, n. 19, p. 20-28, jan. /fev. /mar. /abr. 2002.

LEITE, J.R. Educação por trás das grades: uma contribuição ao trabalho educativa, ao preso e à sociedade. 1997. Dissertaçáo (Mestrado em Educaçáa) - Programa de Pós-Graduação em Ciências Sociais, UNESP, 1997.

MEIHY, J.C.S.B. Manual de história oral. 2a ed. São Paulo: Edições Loyola, 2002.

MELLO, H. de A. O trabalho na prisäo: um estudo no Instituto de reeducação penal Desembargador Sílvio Porto em João Pessoa - PB. Dissertação (Mestrado em Serviço Social) - Programa de Pós-graduaçáo em Serviço Social, UFPB, São Paulo, 2010. 
ONOFRE, E.M.C. Educação escolar de adultos em privação de liberdade: limites e possibilidades. In: Anped, 31., 2008, Caxambu, Anais... Caxambu, 2008. p. 1-16,

PENNA, M.G.O. O ofício de professor: as ambiguidades do exercício da docência por monitores-presos. 2003. Dissertação (Mestrado em Educação) - Programa de Pós-Graduação em Educação, PUC, São Paulo, 2003.

PORTUGUÊS, M.R. Educação de adultos presos: possibilidades e contradiçôes da inserção da educaçáo escolar nos programas de reabilitação do sistema penal de São Paulo. 2001. Dissertação (Mestrado em Educação) - Programa de Pósgraduação em Educação, USP, São Paulo, 2001.

ROCHA, L.C.A Prisão dos Pobres. Tese (Doutorado em Psicologia Social) Instituto de Psicologia, Universidade de São Paulo, São Paulo, 1994.

SÃO PAULO. Fundaçấo Prof. Dr. Manoel Pedro Pimentel. O Programa do Preso. Disponível em: $\leq$ http://www.funap.sp.gov.br/>. Acesso em: 11 jan. 2010.

SILVA, J.C. Uma história oral e aprendizagem educacional no presidio semi-aberto Ataliba Nogueira. Instituto de Filosofia e Ciências Humanas, Departamento de História. Universidade Estadual de Campinas. Campinas. 2000.

SILVA, S.J. da; GÓES, D.G. de; ROCHA, J.R.F. de O. Formação do educador popular em EJA: escola libertadora em Presídio. ALB: X Seminário "Educação de Jovens e Adultos". Campinas, 2007.

RUSCHE, J.R. (Org.). Educação de Adultos Presos: uma proposta metodológica. São Paulo: FUNAP, 1995.

ZANIN, J.E.; OLIVEIRA, R.C.S. Penitenciárias privatizadas: educação e ressocialização. Revista Práxis Educativa, Ponta Grossa, v. 1, n. 2, p. 39-48, jul./dez. 2006.

\section{NOTAS}

1. A Lei 12.433, de 29 de junho de 2011, alterou o artigo 126 da LEP, dando a seguinte redaçáo: Art. 126: "O condenado que cumpre a pena em regime fechado ou semiaberto poderá remir, por trabalho ou por estudo, parte do tempo de execução da pena”.

2. Ver a pesquisa: Educação nas prisōes: perfil de escolaridade da população prisional de São Paulo. São Paulo: Açáo Educativa, 2013.

3. Dois presos monitores são professores formados antes de serem presos. São dois formados em Letras, um homem e uma mulher, e um deles é professor de História. 
4. O preso que estuda reduz um dia de pena a cada 12 horas de frequência escolar — atividade de ensino fundamental, médio, inclusive profissionalizante, ou superior, ou ainda de requalificaçáo profissional - divididas, no mínimo, em três dias. O tempo a remir em função das horas de estudo será acrescido de 1/3 um terço, no caso de conclusáo do ensino fundamental, médio ou superior durante o cumprimento da pena, desde que certificada pelo órgão competente do sistema de educação. De acordo com a Lei no 12.433, de 29 de junho de 2011, a cada três dias trabalhados é descontado um dia da pena (BRASIL, 2011).

5. Como o trabalho do preso não está sujeito ao regime da CLT, o empresário fica isento de encargos como férias, $13^{\circ}$, INSS e FGTS.

6. Os problemas da violência nas prisões, da superlotação foram amplamente denunciados desde os anos 1980 por Paulo Sérgio Pinheiro ver: PINHEIRO, P. S. Escritos Indignados: polícia, prisóes e políticas no Estado Autoritário (No 20 aniversário do Regime de Exceção, 1964-1984). São Paulo: Brasiliense, 1984; e nos anos de 1990 por Sérgio Adorno ver: ADORNO, S. Sistema Penitenciário no Brasil: problemas e desafios. Revista USP, n. 9, p. 65-78, mar./abr./maio 1991.

7. Retornou para a Secretaria da Educação.

Recebido em 11 de septiembre de 2015.

Aceito em 22 de febrero de 2016. 